A summary of this working group report was published as an editorial in the BMJ (Samet FM, Taylor CE, Becker KM, et al. Research in support of tobacco control. BMJ 1998;316:321-2) $<$ http://www.bmj.com/archive/7128/7128e1.htm>. The full report, as reproduced below, is available on the BMF's web site at <http://www.bmj.com/archive/7128/7128ext.htm>.—ED

\title{
Research for effective global tobacco control in the 21st century: report of a working group convened during the 10th World Conference on Tobacco or Health
}

\author{
Conveners: Jonathan M Samet, Derek Yach, Carl Taylor, Karen Becker
}

\section{Introduction}

The 10th World Conference on Tobacco or Health was held in Beijing at a critical juncture for the world's tobacco control movement. Facing a declining market in many Western, developed countries and formidable law suits in the United States, the major tobacco companies of the developed nations have aggressively turned to developing countries as their future markets. This global conference offered a venue for discussion at a time of urgent need for action as marketing of cigarettes by multinational corporations is spreading rapidly throughout the developing world and in central and eastern Europe.

To foster discussion on policy-relevant research, tobacco control experts from throughout the world (see appendix) met intensively during the conference. The participants were policy makers, researchers, tobacco control specialists, and activists, drawn from developing and developed countries from all over the world. Key sectors were represented including academia, public health agencies, non-governmental organizations, and private industry. Two working groups met in parallel throughout the conference: one addressing epidemiological research and intervention studies, and the other, broader policy-related research. The overall objective was to identify the research evidence and public health data with the highest potential to affect tobacco control policy.

Over the past few years, several global and national reviews of priorities for tobacco control, and for tobacco control research more specifically, have been completed. These reports have emphasized the need for cost-effective interventions to be developed for the prevention and control of tobacco use and ultimately of tobacco-attributable disease. Particular attention has been given to the need for information on tobacco use and health impact, identification of the determinants of use and quitting, and the impact of interventions (in terms of efficacy, effectiveness, and occasion- ally, cost-effectiveness), and to the need for investments in human and institutional capacity for addressing tobacco control research and prevention needs. Although there have been other listings of research needs, the emphasis here is on identifying those minimum countryspecific and international elements that are essential for successful tobacco control.

This report summarizes the outcome of the deliberations and is intended as a contribution to other ongoing tobacco control initiatives aimed at ensuring that, globally and within every country, tobacco control is given appropriate priority and is based on sound evidence. Participants in the working groups noted key barriers to the implementation of tobacco control research: a lack of research and data-gathering infrastructure in many countries; inadequate expertise in epidemiology, biostatistics, and health systems; and a nearly complete absence of funds for research directed at the global control of tobacco use and of tobacco-attributable disease. Participants unanimously called for urgent action to remedy these problems. Lacking expertise in tobacco control and even basic data collection, many developing countries are left vulnerable to the aggressive penetration of the multinational tobacco corporations. In developing the recommendations, participants concurred strongly that tobacco control policies need to be evidence-based, drawing from data on the prevalence of smoking and the characteristics of smokers and on the adverse health effects of smoking in the population, and using intervention methods of proven efficacy. Research on tobacco control should reflect a planned, sustained, and comprehensive surveillance strategy put into place to track progress in controlling tobacco use and tobacco-related disease.

Research leading to a new framework for tobacco control policy

A strong consensus reflected the reality that abundant evidence supports immediate implementation of a basic package of strong control 
policies in all countries. Implementation of this package should not await further research. The elements should include banning advertising, restricting smoking in public places, taxing tobacco products at an appropriate level, and establishing governmental and non-governmental foci for action.

Future tobacco control policy research should identify the optimal policy mix for a particular country that explicitly acknowledges national capacity and readiness to implement specific components of an overall tobacco control program. Countries differ widely in patterns of tobacco use and sales and in cultural attitudes and governmental policies towards smoking. A clearer vision of what is achievable in different settings over the medium and long term with regard to controlling tobacco consumption and its effects on health would be part of this process. Many of the individual components of a policy mix have been well-described by the World Health Organization (WHO). The applicability and effectiveness of several components still need to be assessed in countries across a wide range of development. Multidisciplinary research that draws upon economics, political science, sociology, and other disciplines is essential if the current focus on single interventions within a common blueprint is to develop into an approach tailored to the specific needs and capabilities of individual countries.

The readiness of countries to act needs to be assessed through a mixture of qualitative and quantitative research that targets the population (covering support for specific interventions, knowledge of the health effects of tobacco, and the priority they give to tobacco control); politicians, with regard to their recognition of tobacco control as a public priority and one that has economic implications; health professionals, media, and other influential groups that play an important role in setting the public agenda for action. The role of health professionals was emphasized; they are critical as the leaders and the initiators of tobacco control. Assessment of readiness to act at national and local levels constitutes an important and neglected research area.

Research on tobacco control policy needs to draw to a greater extent than in the past on other policy research initiatives in health and development. Specifically, experience gained in several community-based approaches to health and development (including "Healthy Cities and Villages" and work on social capital) should be systematically reviewed and assessed to determine what these approaches offer to sustainable community-based tobacco control. Multiple risk factor interventions (especially among youth) should be assessed as to their effectiveness in achieving overall improvements on health practices and behaviors over the lifespan of individuals. In countries where tobacco cultivation is prevalent, research should also address substitution of other crops and draw from work related to changing agricultural practices more generally.

Country-specific evidence needs to be complemented by a much stronger focus on the transnational determinants of tobacco use and on research to develop transnational approaches to control. A timely starting point would be a deeper understanding of the consequences of successes in tobacco control in countries that are home to major multinationals on the behavior of the multinationals elsewhere. Also requiring urgent assessment are trade flows; the extent to which national borders are permeable to global marketing and promotional activities; the impact of differential tax and price levels among countries on smuggling; and effects on countries' tobacco consumption of being required to meet current World Trade Organization rules. This work is particularly relevant for driving the development of the WHO Framework Convention for Tobacco Control, which could afford a global policy. Additional comparative international law research is needed to identify criteria of successful implementation of international conventions and regulations by other United Nations agencies. Neighboring countries may face similar challenges from the multinationals and regional research networks may facilitate tobacco control. The networks could foster information sharing and joint research efforts.

Several global gaps in research could be filled rapidly and provide information that could accelerate policy development. Five examples are given. First, data on children should be aggregated and policy implications evaluated. These data include the current knowledge on the health impact of smoking on children in developing countries, the age and determinants of initiation in children in developing countries and the practicability of restricting children's access to tobacco in developing countries. The findings of this review could increase the likelihood of international United Nations Children's Fund (UNICEF) action in tobacco control. Second, research is needed on how to maintain the presently low-smoking rates among women. In many Asian countriesChina for example - only a few percent of women smoke. They represent a large potential market but have received little attention in research on smoking prevention. Third, the relationship between successful quitting by adults and the rate of initiation of smoking by their children needs to be characterized. The findings of this work could provide a unifying element for cessation and preventive strategies. Fourth, the role of litigation and its relevance to countries at various stages of development needs assessment. Recent events in the United States make this a priority area for policy research. Fifth, policy analyses should be conducted to identify successes in implementing tobacco tax policies to support research and tobacco control initiatives. The lessons learned may prove useful for other countries.

\section{Observational studies and intervention} trials

OBSERVATIONAL STUDIES

Surveys

Surveys of smoking are essential as the base for tobacco control initiatives; they provide information on the prevalence of smoking, the characteristics of smokers, the knowledge and 
attitudes of smokers, and the willingness of smokers to quit smoking. Collection of survey data should generally be given higher priority than other types of data collection relevant to tobacco control. Three types of surveys are recommended as the basic foundation for tobacco control:

1. General population surveys. General population surveys should be given the highest priority. A standardized and replicable population-based survey methodology is needed to describe the extent of tobacco use and to provide a baseline for tracking tobacco use in the population. The study population should be of sufficient size to provide stable age- and sex-specific prevalence estimates. Unless warranted by unusual circumstances, surveys conducted every five to 10 years should adequately track tobacco use. However, more frequent surveys may be warranted by aggressive tobacco marketing or the need to track the impact of interventions expected to rapidly affect smoking. General population surveys can be supplemented by additional questions targeted at specific issues, such as awareness and impact of advertising or preferences for specific smoking cessation modalities.

2. Surveys of health care providers and others concerned with public health. Whether in the public or private sectors, health care providers and public health workers generally should be exemplars by not smoking. Evidence indicates that if they are smokers, then they are less likely to intervene and to deter their patients from smoking. In many countries, health care providers can be surveyed readily through professional organizations or hospitals. Health care and public health professionals, particularly if their smoking rates are high, should be among the first targets for intervention. If follow-up is possible, a large survey could become the starting point for a prospective cohort study.

3. Children's surveys. In many countries, smoking begins in childhood with experimentation and then with initiation of regular smoking during adolescence. School-based surveys can be conducted feasibly to determine smoking rates and factors influencing the decision to smoke, including the impact of tobacco advertising and other promotional activities. The findings of school surveys of children should guide the development and implementation of prevention programs.

Studies of adverse health effects

Although smoking is a well-documented cause of disease and ill health, there may be a need to reaffirm that smoking causes disease in the populations of specific countries. Policymakers and politicians may question the relevance of findings of studies conducted many years ago and in other populations. The conduct of studies locally should not delay the implementation of tobacco control measures; rather, the local evidence, when available, may provide further support for tobacco control policies. While studies may not be indicated for all locales, data are needed to reflect worldwide population diversity.

Tobacco smoking has diverse effects on morbidity and mortality. Policy may be most affected by evidence on mortality, but morbidity effects should not be overlooked, as they have major effects on productivity, quality of life, and health care costs. However, priority should be given to studies of mortality. For measuring the adverse effects of smoking, two major approaches have proved feasible and informative. Large prospective cohort studies have been central in characterizing the adverse effects of smoking and, in developing countries, these studies can characterize the evolution of the epidemic over a period of decades. If study rosters can be matched readily against death registers, the overall and cause-specific risks associated with smoking can be measured, but in general this will not be possible and active follow-up every few years will be needed. Sustained funding is needed for such studies.

Case-control studies of specific diseases can be conducted through health care facilities, including hospitals and clinics. Careful attention to control selection is needed. If information on smoking can be obtained on deceased persons, the case-control approach can be used to identify the mortality risk associated with smoking. Routinely capturing smoking information on the death certificate would enormously facilitate the conduct of retrospective studies. Even a simple question as to whether the deceased person had smoked at all or five or 10 years ago would suffice.

INTERVENTION STUDIES

Tobacco control is accomplished through programs directed at individuals, communities, and entire countries. Individually directed modalities, such as education and behavioral approaches, and nicotine replacement therapy should complement population-level approaches, ranging from community-education programs to national-level initiatives, such as regulation and taxation. The emphasis on specific interventions should reflect what constitutes the optimal mix for a country at the particular time. For example, in some groups in specific countries-e.g., women in Asia and Africa-interventions should be directed at maintaining their largely non-smoking status. Programs for tobacco control, whether directed at smoking cessation or tobacco control, should have evaluation plans and mechanisms in place so that the mix of interventions can be modified over time.

Experience in a number of countries, primarily more developed and western countries, provides a large body of evidence on strategies for individual smokers, including nicotine replacement therapy. However, the relevance of these data for the full range of other settings is uncertain. There may be differences in the nature of nicotine addiction across populations, perhaps reflecting the doses of nicotine delivered by various types of tobacco products, as well as culturally based differences in the role of smoking, preferences 
in smoking cessation modalities, and perceptions of the symptoms of nicotine withdrawal. Nonetheless, research is needed to find the most effective country-specific modalities to increase the percentage of smokers who want to quit and to assess quitting methods.

Cessation trials should not be undertaken without some understanding of the issues above-i.e., the descriptive characteristics of nicotine addiction and withdrawal. Concern was expressed that intervention trials designed without development of these basic data may be uninformative or misleading. The participants agreed that the needed information could be feasibly obtained using available research methods and that the investment of time, perhaps several years, and of financial resources would lead to more informative and certain results from intervention studies.

The participants recommended a multidisciplinary approach to data gathering that might involve epidemiologists, psychologists, clinicians, and social scientists and cultural anthropologists. A prevalence survey could provide the starting point for data collection, with nested sampling of subgroups of interest. A standardized approach was recommended so that findings could be compared across populations. Recommended elements of the approach included measurement of plasma nicotine in a sample of smokers so as to determine the mean nicotine level and the relationship between smoking pattern and nicotine level; an assessment of barriers to cessation; and a qualitative characterization of cessation to develop an in-depth understanding of factors determining successful and unsuccessful quitting.

The group did not recommend specific types of trials at this time. Participants recommended that the systematic cataloging of trial methods and results be considered, both to ensure that proper syntheses of the evidence could be prepared and to facilitate access to study materials.

\section{Strengthening the implementation process}

To ensure that evidence leads to action, the eventual application of the findings should be in focus from the start of a research project. Early identification and involvement of key stakeholders is likely to increase the chances of successful implementation of research and application of findings. A wide range of research partners should be sought. At national levels, in addition to the ministry of health, the ministries of finance, trade, education, and agriculture should be engaged in the research process. Sharing of information of mutual interest between the public and private sectors should be encouraged and active support of non-governmental organizations should be obtained early.

At the global level, in addition to the crucial role of the WHO, the World Bank, World Trade Organization, United Nations Conference on Trade and Development, United Nations Children's Fund, Food and Agricul- tural Organization, and United Nations Educational, Scientific, and Cultural Organization are increasingly interested in joint initiatives in tobacco control research. The World Bank's recent recognition of the need to support work on the causes, consequences, and costs of tobacco use at a national and global level provides an important opportunity for interaction.

\section{Capacity development}

Capacity development is urgently needed in many countries. Experiences in several countries show that a few, or even just one, trained and committed tobacco control professionals can have substantial impact. However, within many developing countries there is not even one individual working full time on tobacco control, and research capacity for public health in general is too often weak. The few researchers active in many countries work in weak institutions, and have multiple demands on their time that too often crowd out tobacco control research. In many countries, national research bodies give low priority to tobacco control in general and policy research more specifically. Within such a generally unsupportive environment, capacity development for tobacco control research typically suffers.

To avoid duplicating past mistakes in building sustainable capacity, it is vital to learn about the reasons for success/failure in other programs that may be applicable to tobacco control research. Further, the possibility of linking development of tobacco control capacity to other public health research programs needs serious consideration. The expertise within countries having a strong capability in tobacco policy research should be drawn upon to build global capacity. In doing so, new forms of pairing between institutions at varying levels of capability should be considered and tested.

At the global level, there are few economists, lawyers, and trade experts involved in transnational issues related to health. Expertise in these areas needs to be developed using institutions in countries most affected by the negative consequences of trade on health as the starting point. This would allow for centers of excellence and relevance to be established in developing countries.

\section{Financing tobacco control research}

A major global investment in tobacco control research is needed. Consideration should be given to the global institutional structure for housing and supporting the needed initiative. Options need to be considered for the involved institutions and their locations in order to facilitate global capacity development. An appropriate starting point, however, would be to have a small, international group facilitating the work of a network of centers for tobacco control from a range of countries. New telecommunications systems, if used optimally, should ensure a constant flow of ideas and information among researchers. 


\section{Recommended follow-up policy actions and research needs}

The following listing comprises both policy-oriented actions and research recommendations. Given the present urgency to implement tobacco control programs throughout the developing world, the participants added policy-related actions to the research recommendations.

\section{POLICY ACTIONS}

1. Immediate mobilization of potential donors and supporters should be a priority follow-up action of the meeting. International organizations such as WHO and the World Bank could with selected other donors such as the Canadian-led International Tobacco Initiative convene a meeting aimed explicitly at mobilizing international support for a global tobacco control research initiative. New partners should be motivated to support tobacco control research. These could include internationally active foundations, bilateral donors, the private sector, and specifically manufacturers of nicotine replacement therapies or other cessation products, and international non-governmental organizations.

2. The meeting on "The Economics of Tobacco Control: Towards an Optimal Policy Mix" held in Cape Town on 1 February 1998, offered an opportunity to further elaborate a new framework for tobacco control policy research.

3. A focus for action on tobacco in each country should be organized outside of the government. In China, the program organized by the Chinese Association on Smoking and Health (CASH) has been tremendously effective. Providing a focus for action outside government offers a potential counter to parties within government that may be benefiting from tobacco sales, i.e., those concerned with government finances.

4. A government office on smoking and health should be established in each country. However, more than a central office is needed; activities should extend from the national level down to the local.

5. Minimal action steps needed universally should be designated. For example, every country needs a national prevalence survey. There is an immediate need for definition of universally needed minimal action steps, such as banning advertising, both direct and indirect, and restricting smoking in public places.

6. Steps should be taken to establish a supportive environment for tobacco control. Public opinion needs to be motivated and support is needed at all levels of society for tobacco control.

7. Steps need to be taken to educate health professionals as role models for smoking prevention. Their own smoking needs to be addressed and all need an adequate understanding of the tobacco epidemic.

8. A complete inventory should be developed to establish a network of leaders of tobacco control programs. There are many good networks already in place and active, but synthesis is needed and cooperative linkages should be established.

9. Creative new alliances should be built to address smoking as one of the most urgent international problems.

10. Organizations concerned with women and children should be mobilized around the tobacco epidemic.

11. Non-governmental organizations and professional organizations need to be strongly motivated to take leadership on this, the world's greatest epidemic.

\section{RESEARCH RECOMMENDATIONS}

1. The tobacco industry itself needs to be investigated. Approaches should be developed for gathering evidence on tobacco industry actions in terms of trade flows, marketing, and the buying of influence.

2. The proper mix of policies for local tobacco control should be determined. Relevant evidence is needed, as each country may have specific and differing needs. The policy mix should be responsive to local culture and administration, and to the status of the tobacco epidemic.

3. Transnational factors influencing smoking need urgent investigation. The data are needed to support transnational responses to the marketing of cigarettes throughout the developing world.

4. Control measures for cessation and prevention need to be properly balanced. More in-depth studies of smoking and addiction in different countries and cultures are needed.

5. The right balance between top-down and bottom-up approaches needs to be found. There should be both central and local activities and community-based action.

6. Multidisciplinary research on smoking is needed across countries as the basis for designing the most effective intervention studies.

7. A planned World Bank initiative aimed at updating its policy on tobacco control could allow for more rapid identification of research gaps and missed opportunities.

RESEARCH FUNDING

1. Within all countries a wider array of funding sources should be identified. These include using excise tax on tobacco for research, and ensuring that local research councils and foundations give priority to tobacco control research.

2. Tobacco tax policies with appropriate allocation of funds were regarded as the most important single priority for continuous, sustained funding.

3. Creative partnerships with corporate and other donors are needed. For example, manufacturers of nicotine-replacement therapy or other smoking cessation modalities represent potential partners for public health alliances.

4. There should be an international allocation from any legal settlements in the United States or other developed countries. 
Developing countries must not suffer negative consequences from the settlements and should receive money for anti-tobacco programs from the large sums that will be paid out.

This working group was supported in part by a grant from SmithKline Beecham.

List of participants

Mira B Aghi-India

Abdullah MN Al-Bedah-Saudi Arabia

Gallege Punyawavdana Alvis-Sri Lanka

Veuqoe Bradley-USA

Simon Chapman-Australia

Wang Chen-China

Yau Chonghua-China

Chen Chunming - China

Neil Collishaw-Switzerland

Elif Dagli-Turkey

Joe Gitchell-USA

Yang Gonghuan-China

AI Islam-Bangladesh

Martin Jarvis-United Kingdom

Guo Jing Xuan-China

Luk Joossens-Belgium

Zhou Kan-China

Wang Ke-an-China

Eva Kralikova-Czech Republic

Tai Hing Lam-Hong Kong, China

Witold Zatoński-Poland

Lisa Lauter-China
Judith Longstaff Mackay-Hong Kong, China Halfdan Mahler-Switzerland

Joseph McGovern-USA

Garrett Mehl—Sri Lanka

Thomas Novotny-USA

Mrigendra R Pandey-Nepal

Richard Peto-United Kingdom

Krztsztof Przewozniak-Poland

Horacio Rubio Monteverde-Mexico

Jonathan M Samet-USA

Raol H Sansores-Mexico

Cecilia Sepulveda-Chile

Saul Shiffman-USA

Chris Silagy-Australia

David Simpson-United Kingdom

Karen Slama-France

Tomas Stanikas-Lithuania

Krisela Steyn - South Africa

Ken Strahs-USA

Carl Taylor-USA

Jaihe Villalba-Gloca-Mexico

Xinzhi Wang-Argentina

Kenneth E Warner-USA

Judith Watt-Australia

Richard Windsor-USA

Stephen Woodward-USA

Chonghua Yao-China

Zarihah Zain-Malaysia

David Zaridze-Russia

Hong-yu Zhang-China

Wu Zhaosu-China

World's leading unmanufactured tobacco producing, trading, and consuming countries (metric tons dry weight)

\begin{tabular}{|c|c|c|c|c|c|}
\hline & 1993 & 1994 & 1995 & 1996 & $1997^{\star}$ \\
\hline \multicolumn{6}{|l|}{ Production } \\
\hline World total & 7325157 & 5609552 & 6579289 & 5547668 & 7312915 \\
\hline China, People's Republic of & 3118000 & 2000000 & 2082600 & 2910600 & 3315600 \\
\hline United States & 651511 & 641181 & 513247 & 625454 & 667680 \\
\hline India & 522540 & 475200 & 528390 & 506475 & 544050 \\
\hline Brazil & 509000 & 365000 & 323500 & 367000 & 497053 \\
\hline Turkey & 280803 & 155818 & 170070 & 190391 & 245260 \\
\hline Zimbabwe & 201992 & 152490 & 179243 & 178605 & 165240 \\
\hline \multicolumn{6}{|l|}{ Exports } \\
\hline World total & 1735554 & 1694877 & 1768823 & 1956381 & 1924745 \\
\hline Brazil & 243500 & 275500 & 256300 & 282500 & 294000 \\
\hline United States & 207747 & 196792 & 209482 & 222316 & 221509 \\
\hline Zimbabwe & 188261 & 203485 & 174289 & 195958 & 175572 \\
\hline Turkey & 91350 & 112411 & 136392 & 170098 & 156200 \\
\hline India & 91000 & 22390 & 77680 & 118000 & 115000 \\
\hline Italy & 124563 & 110332 & 118839 & 138829 & 107000 \\
\hline \multicolumn{6}{|l|}{ Imports } \\
\hline World total & 1765584 & 1786902 & 1797557 & 1977436 & 1939307 \\
\hline United States $†$ & 359738 & 264390 & 199088 & 326455 & 306838 \\
\hline Germany $\ddagger$ & 154175 & 182785 & 209761 & 235855 & 250000 \\
\hline Russian Federation & 144125 & 143080 & 148110 & 125296 & 148800 \\
\hline United Kingdom & 124324 & 97958 & 141467 & 166027 & 131876 \\
\hline Netherlands & 83623 & 86546 & 89075 & 97368 & 97500 \\
\hline Japan & 118651 & 135543 & 115072 & 85634 & 96000 \\
\hline \multicolumn{6}{|l|}{ Consumption } \\
\hline World total & 6958079 & 6860867 & 6332896 & 6504763 & 6303870 \\
\hline China, People's Republic of & 2907029 & 2808734 & 2208554 & 2313705 & 2115134 \\
\hline United States & 725241 & 667146 & 699200 & 714138 & 710000 \\
\hline India & 426045 & 438605 & 463920 & 472070 & 478760 \\
\hline Indonesia & 139733 & 165786 & 183050 & 196670 & 200550 \\
\hline Japan & 179235 & 190000 & 196900 & 197250 & 195700 \\
\hline Brazil & 143000 & 152500 & 166900 & 179400 & 187400 \\
\hline
\end{tabular}

Source: US Department of Agriculture, Foreign Agricultural Service, Circular Series FT-02-98, February 1998, Table 1, page 8. ^Estimate.

†General imports (actual arrivals).

‡Unified Germany. 